2012-04-01

\title{
An Attentional Control Task Reduces Intrusive Thoughts About Smoking
}

May, Jon

http://hdl.handle.net/10026.1/987

10.1093/ntr/ntr238

Nicotine \&amp; Tobacco Research

Oxford University Press (OUP)

All content in PEARL is protected by copyright law. Author manuscripts are made available in accordance with publisher policies. Please cite only the published version using the details provided on the item record or document. In the absence of an open licence (e.g. Creative Commons), permissions for further reuse of content should be sought from the publisher or author. 


\section{OXFORD Nicotine \& \\ UNIVERSITY pREss Tobacco Research}

This is the originally submitted pre-review manuscript of:

May, J., Andrade, J., Willoughby, K. \& Brown, C. (2012) An attentional control task reduces intrusive thoughts about smoking. Nicotine \& Tobacco Research, 14(4), 472-478. doi: 10.1093/ntr/ntr238

The published version differs from this copy so please do not treat this as definitive.

\section{Body scanning reduces intrusive thoughts about smoking}

\begin{tabular}{|r|l|}
\hline Journal: & Nicotine \& Tobacco Research \\
\hline Manuscript ID: & Draft \\
\hline Manuscript Type: & Original Investigation \\
\hline Date Submitted by the & $\mathrm{n} / \mathrm{a}$ \\
\hline Complete List of Authors: & $\begin{array}{l}\text { May, Jon; University of Plymouth, School of Psychology } \\
\text { Andrade, Jackie; University of Plymouth, School of Psychology } \\
\text { Willoughby, Kimberley; University of Plymouth, School of } \\
\text { Psychology } \\
\text { Brown, Christopher; University of Plymouth, School of Psychology }\end{array}$ \\
\hline Keywords: & Attention, Addiction, Mindfulness, Craving \\
\hline
\end{tabular}

\section{SCHOLARONE ${ }^{\text {Im }}$ Manuscripts}




\title{
Body scanning reduces intrusive thoughts about smoking
}

\author{
Jon May \\ Jackie Andrade \\ Kimberley Willoughby \\ Chris Brown \\ School of Psychology, \\ University of Plymouth \\ Contact Author: \\ Professor Jon May, jon.may@plymouth.ac.uk \\ School of Psychology \\ University of Plymouth, \\ Drake Circus \\ Plymouth \\ UK- PL4 8AA
}

Declaration of interest: This research was supported by the University of Plymouth. We declare no conflicts of interest.

Keywords: Attention, addiction, mindfulness, craving

Running Head: Body scanning reduces intrusive thoughts

Abstract: 236 words

Word Count: 3100

Tables: none

Figures: 2 
Body scanning reduces intrusive thoughts

\begin{abstract}
Introduction: Body scanning and isometric exercise instructions have been shown to reduce smoking cravings, apparently by reducing stress (Ussher et al., 2009). Related work based upon Elaborated Intrusion theory (Kavanagh, Andrade \& May, 2005) has shown that attentional control instructions can reduce hungry participants' spontaneous food-related thoughts (May et al., 2010). This study tests the effect of body scanning upon smoking related thoughts, as well as craving.
\end{abstract}

Method: 27 smokers took part in two counterbalanced sessions, on different days. In each session they followed audio instructions for three ten minute blocks, during which their thoughts were probed ten times. In the first and third blocks, they were instructed to let their mind wander; during the second block of the control session they also let their mind wander but in the experimental session they followed body scanning instructions. Smoking thought frequency was assessed using thought probes; Craving was measured using Factor 1 of the Questionnaire of Smoking Urges (Tiffany \& Drobes, 1991).

Results: In the body scanning block participants reported fewer smoking related thoughts and lower smoking cravings; intrusions and craving rebounded above baseline for both sessions in the final period of mind wandering.

Conclusions: Body scanning reduces cravings through reducing the frequency or shortening the duration of smoking thoughts. If the cognitive mechanism by which body scanning reduces intrusive thoughts can be identified, attentional control strategies may form a useful part of future smoking cessation practices. 
Body scanning reduces intrusive thoughts

Introduction

Quitting smoking is very hard to do: without any help, around 3-6\% of smokers succeed in a quit attempt; the most successful interventions, group therapy or prescription of Buproprion, double it - but around 90\% still fail (Lemmens, Oenema, Knut, \& Brug, 2008). Smokers often report that their attempts to abstain are defeated by severe cravings (Killen $\&$ Fortman, 1997; Zhou, Nonnemaker, Sherrill, et al,. 2009). Urges to smoke increase in the days leading to relapse and can occur long after any physiological effects of nicotine withdrawal have ceased (Shiffman, Engberg, Paty, et al., 1997), and severity of craving is associated with relapse (West, Hajek \& Belcher, 1989). This paper reports a cognitivelymotivated approach to smoking cessation, based upon Elaborated Intrusion theory (Kavanagh, Andrade \& May, 2005).

Many approaches to smoking cessation include behavioural change techniques alongside medication, but often with weak theoretical motivation (West, Walia, Hyder, Shahab \& Michie, 2010). A meta-analysis of randomized controlled trials indicated that teaching strategies to control cravings can be helpful (U.S. Department of Health and Human Services, 2008). The incentive-sensitization theory of addiction also indicates that behavioural approaches to addiction 'may offer the best hope for addicts today' (Robinson \& Berridge, 2000, p.S109), given the apparently irreversible neural sensitization effects of addictive drugs.

One such approach evaluated by Ussher, Cropley, Playle, Mohidin \& West (2009) involved asking abstaining smokers to follow ten minutes of audio instructions to engage in isometric exercises (contracting specific muscle groups while seated, without actively moving around) or body scanning (directing attention towards specific parts of the body while remaining motionless, and without any muscular demands). These both reduced desire to smoke for up to 30 minutes following the intervention, and were also effective when selfadministered by participants outside the laboratory. The rationale for the intervention was that stress is likely to exacerbate the desire to smoke, and that physical exercise is known to reduce stress: isometric exercises and body scanning might reduce smoking cravings by reducing stress. In a review paper, Taylor, Ussher \& Faulkner (2007) had found that 12 studies that compared a bout of exercise with a passive condition reported a positive effect on cigarette cravings, withdrawal symptoms and smoking behaviour, and argued that the effects did not appear to be due to distraction or arousal, but occurred through a reduction of stress and negative affect. Ussher, West, Doshi and Sampuran (2006) had found that a brief session 
Body scanning reduces intrusive thoughts

of isometric exercises (tensing muscle groups while seated, but without actively moving) reduced cigarette cravings, relative to a passive control, but that a body scanning exercise had intermediate effects, differing neither to the control nor the exercise group. The body scanning task had been intended to be a control task similar to the isometric exercises but without muscular exertion: the lack of difference with the isometric condition was unexpected. Participants had been instructed at the start of the session to focus their attention to five different parts of the body in turn, and Ussher et al (2006) note that is not possible to tell whether their participants were able to comply with this task for the full ten minutes, whereas it is possible to observe participants engaging in the isometric exercises. Although the findings from this early study were inconclusive, it did raise the possibility that body scanning might actually be having an unexpected effect in reducing cravings. Ussher et al. (2009) appear to have enhanced the effectiveness of the body scanning condition by guiding their participants through the scanning with regular audio instructions about the locations to which to focus their attention.

We reported a related study, albeit with a different rationale and in the domain of appetite (May, Andrade, Berry, Batey \& Kavanagh, 2010). In two experiments, we asked undergraduates who had delayed a meal to follow audio instructions engaging them in various mental tasks. Self-directed and guided imagery, body scanning, and thought suppression all reduced the proportion of food-related thoughts reported by hungry participants (although the effects did not carry through to a reduction in food craving). The rationale for this study was drawn from our Elaborated Intrusion Theory of Desire (Kavanagh, Andrade \& May, 2005), which argues that craving for addictive and non-addictive substances begins with unconscious mental activation, which may give rise to the intrusion into conscious awareness of a desirerelated thought. Apparently spontaneous intrusive thoughts are known to be linked to cravings for smoking, alcohol and eating (May, Andrade, Panabokke \& Kavanagh, 2004). Depending upon task demands, this initial intrusion may be followed by cognitive elaboration, and in particular visual imagery of the target. A number of studies have now shown that interfering with this visual imagery can reduce craving in abstaining smokers (May, Andrade, Panabokke, \& Kavanagh, 2010; Versland \& Rosenberg, 2007), dieters (Kemps, Tiggemann, Woods, \& Soekov, 2004) and undergraduates induced to crave food or chocolate (Kemps \& Tiggemann, 2007).

Elaborated Intrusion theory predicts that approaches targeted at intrusive thoughts will also be effective in reducing craving-driven substance use. Suppressing unwanted thoughts is 
Body scanning reduces intrusive thoughts

a natural but often counter-productive strategy (e.g., Salkovskis \& Reynolds, 1994). instructions to ignore thoughts have been shown to be effective in reducing snacking (Achtziger, Gollwitzer \& Sheeran, 2008), but whether the effect is mediated by effects on craving has not been tested. Mindfulness-based techniques, such as body scanning, potentially offer a way of reducing the occurrence and elaboration of intrusive thoughts by encouraging awareness of a wide range of competing thoughts and sensations. The studies by Ussher et al. (2006), Ussher et al., (2009) support this prediction from Elaborated Intrusion theory by showing that guided body scanning, in which participants' compliance is enhanced by the use of regular instructions, is effective in reducing smoking cravings. May et al. (2010) did not find an effect of body scanning upon craving for food, but did find an effect upon food related thoughts. It is possible that the effectiveness of the body scanning condition upon smoking is also due to a reduction in smoking related thoughts. In this paper, we replicate the findings of Ussher et al. by showing that the body scanning instructions used by May et al. also reduce smoking cravings, and extend it be showing that they do so by reducing intrusive thoughts about smoking, in line with the predictions of Elaborated Intrusion theory.

Method

This study received ethical approval from the University of Plymouth School of Psychology Ethics Committee. 27 volunteers (mean age 29 years; 11 Male) took part in two individual sessions, on different days, each lasting 45 minutes. Twelve were recruited from the general population and received no incentive; 15 were undergraduate psychology students who each received a participation point that they could use to reward participants in their own research. All volunteers were regular smokers who reported smoking at least 10 cigarettes a day. Before taking part in the first session, each participant read a briefing form explaining the purpose of the experiment, and gave signed consent.

Participants were asked to abstain from smoking for at least two hours before attending a session. At the start of both sessions, participants' breath $\mathrm{CO}$ was measured using a Bedfont Micro-Smokerlyser (Bedfont Scientific Ltd., Rochester UK). They then completed a questionnaire about their smoking habits and gave their packet of cigarettes to the experimenter, who placed them out of sight in a drawer for the duration of the session. This procedure was intended to increase the likelihood of smoking related thoughts during the session. 
Body scanning reduces intrusive thoughts

Each session then consisted of three blocks, during which participants listened to a ten minute recording, containing statements every twenty seconds. Ten of the statements were followed after a brief interval by a bell, cueing participants to report in a word or two whatever had been passing through their mind when they heard the bell. This was transcribed by the experimenter and, at the end of the session, categorised by the participant as related or unrelated to smoking. Following each block, participants completed the 15 items comprising Factor 1 from the Questionnaire on Smoking Urges (QSU; Tiffany \& Drobes, 1991), rating each item on a scale ranging from 1 (strongly disagree) to 7 (strongly agree).

The recordings in the first (Baseline) and third (After) blocks in each session consisted of 'mind wandering' instructions (May et al 2010, Appendix B3), for example. "Following any thought that comes along. Just watching thoughts drift through your mind. Thinking about anything your mind wants to. Let your mind wander wherever it will go". The middle (During) block of the control session also used the mind wandering instructions, but in the experimental session a set of body-scanning instructions was used (May et al 2010, Appendix B1). Participants were instructed to direct their attention around their body, becoming aware of any sensations, for example, "Now directing your attention to the toes of your feet. Tuning into sensations in your toes, noticing how they feel. Noticing whatever sensations are here, right now. Now on an out breath, letting go of the toes, moving your focus to the bottom of your feet, the soles, and heel. Staying here, paying attention to any sensations you find". The order of sessions was counterbalanced over participants.

\section{Results}

The maximum recorded breath $\mathrm{CO}$ was $16 \mathrm{ppm}(\mathrm{M}=9.00, \mathrm{SD}=5.3)$, indicating that participants had complied with the abstinence instructions. Overall, participants reported a mean of 3.7 smoking related thoughts $(\mathrm{SD}=2.5)$ during a ten minute block, and a mean craving of $5.9(\mathrm{SD}=1.1)$ at the end of a block.

A Multivariate ANOVA (SPSS 18.0) with the within-subject factors of Session (Control, Experimental) and Block (Baseline, During, After) was conducted on the number of smoking related thoughts occurring during each block of the two sessions, and upon the mean QSU craving score at the end of each block. Overall there was a main effect of Block (Mult $F(4,25)=12.39, p<.001, \eta^{2}=.683$ ) and an interaction of Block x Session (Mult $\left.F(4,23)=2.81, p=.049, \eta^{2}=.328\right)$. Univariate ANOVAs repeated this pattern for both Smoking related thoughts (Block: $F(2,52)=20.54, p<.001, \eta^{2}=.441$; Block x Session: $F(2$, 
Body scanning reduces intrusive thoughts

52) $\left.=4.55, p=.015, \eta^{2}=.149\right)$ and Craving (Block: $F(2,52)=13.29, p<.001, \eta^{2}=.338$;

Block x Session: $\left.F(2,52)=3.94, p=.026, \eta^{2}=.132\right)$.

Inspection of the means indicated that smoking related thoughts remained level during the three blocks of the control session, but fell during the body-scanning recording in the experimental session (Figure 1 shows the frequency of smoking related thoughts occurring in each block, and Figure 2 the craving ratings following each block). To validate this interpretation, separate repeated measures ANOVAs were conducted upon the number of thoughts and craving ratings from each session, with planned polynomial contrasts on the levels of Block (Baseline, During, After; significant Linear contrasts indicate that the measures were higher during or after the final mind-wandering block than the initial block; significant Quadratic contrasts that the measures were lower during or after the middle block than the other two.)

During the Control session, there was no effect of Block upon thought frequency $\left(F(2,52)=1.69, p=.194, \eta^{2}=.061\right)$, but there was upon craving $(F(2,52)=10.02, p<.001$, $\left.\eta^{2}=.278\right)$. For craving, the Linear contrast was significant $(F(1,26)=11.92, p=.002$, $\left.\eta^{2}=.314\right)$, but the Quadratic contrast was not $(\mathrm{F}<1)$. Thus no change in smoking related thoughts was detectable, but craving rose throughout the control session.

During the Experimental session, there were significant effects of Block upon both thought frequency $\left(F(2,52)=17.36, p<.001, \eta^{2}=.400\right)$ and $\operatorname{craving}(F(2,52)=8.78$, $p=.001, \eta^{2}=.252$ ). The Quadratic contrast was also significant for both measures (thought frequency: $F(1,26)=22.48, p<.001, \eta^{2}=.464$; craving: $F(1,26)=8.16, p=.008, \eta^{2}=.239$ ), as was the Linear contrast (thought frequency: $F(1,26)=7.85, p=.009, \eta^{2}=.232$; craving: $\left.F(1,26)=10.11, p=.004, \eta^{2}=.280\right)$. Thus both thoughts and craving were reduced during the intervention block, but rebounded above Baseline after the intervention.

To compare the rise in thought frequency and craving from the baseline to after blocks over sessions, further ANOVAs were conducted omitting the middle 'during intervention' block. Now there were main effects of Block for both measures (thoughts: $F(1,26)=6.75$, $p=.015, \eta^{2}=.206$; craving: $\left.F(1,26)=17.87, p<.001, \eta^{2}=.407\right)$ but no effects of Session or any interaction. Thus the rise in thoughts and craving found in the body scanning session was not significantly larger than that occurring in the control session. 
Body scanning reduces intrusive thoughts

\section{Discussion}

Our results indicate that thoughts about smoking were reduced during the body scanning block, and craving also decreased. During the subsequent ten minutes of mindwandering, smoking thoughts and craving rose above baseline in both the control and body scanning sessions, but did so equally. Thus the reduction in thoughts and craving caused by the body scanning did not persist into the following ten minute period, but neither did it exacerbate the rise in both measures that occurred in the control session.

This paper advances our understanding of craving as a general phenomenon of motivated behaviour by linking research in the domains of tobacco addiction and eating disorders, and strengthens the argument that it has a cognitive basis, triggered by physiological and affective cues. The abuse of addictive substances is often attributed to basic physiological changes, and to the pharmacological or neurological effects of psychoactive substances, with cognitive processes or resources having a limited, epiphenomenal role. Eating disorders, in contrast, are seen as essentially psychodynamic, as a response to irresolvable trauma or issues of control and self worth. Elaborated Intrusion theory argues that cognitive processing is crucial in both, mediating the link between situational, cognitive or physiological cues and the moment to moment conscious experience and desires of the individual. Interventions that address the individual's experience of and response to intrusive thoughts about a problematic behaviour offer a focussed way of moderating a wide range of apparently compulsive activities, and perhaps also of inciting positive health related behaviour.

There are a number of further avenues of research that arise from this paper. As in May et al (2010), we have here shown that body scanning is an effective way of temporarily reducing spontaneous craving-related thoughts, and as in Ussher et al. (2009), there was an immediate reduction in craving. If the craving were causing the thoughts, then this would not be surprising, but May et al. (2010) did not find a reduction in food cravings, and so this does not seem to be the explanation. Evidence that intrusive thoughts occur when limited-capacity, executive processing demands are low comes from Antrobus's (1968) demonstration that participants reported more intrusive thoughts during a tone detection task with slower presentations or fewer tones. Teasdale and colleagues extended this research by comparing the incidence of such thoughts under conditions of verbal or visual task loads. Their studies showed that it was the amount of information to be held in working memory, rather than the modality of that information, that determined intrusion rate (Teasdale, Proctor, Lloyd \& 
Body scanning reduces intrusive thoughts

Baddeley, 1993), and concluded that such thoughts only reached awareness if they were able to access central executive resources. By engaging the individual in a focused task, with frequent cues to reorient them to the task, the audio instructions used in our experiments and by Ussher et al. (2009) might occupy central executive resources and so leave no opportunity for task-irrelevant thoughts to reach awareness; any thoughts that do occur may not be followed by elaboration due to the high imagery load imposed by the primary task, and so may be of briefer duration. Thought probe measures cannot distinguish between a true reduction in thought frequency and a change in the duration of thoughts: if the same number of thoughts occur, but are all shorter in duration, then they are less likely to be in awareness when a probe occurs (in much the same way as a pedestrian crossing a railway bridge several times a day will notice more slow freight trains than the faster but more frequent express trains). Other approaches to measuring intrusive thought frequency are even more prone to bias, however: retrospective reports cannot record brief thoughts that are not recalled; and asking participants to monitor their own thoughts increases intrusions (Wegner, 1989). Resolving this issue may well require a new approach to measuring intrusive thoughts, perhaps using probes that are contingent upon some measure of mental activity, from EEG or cortical blood-flow.

This study did not measure participants' mood, whereas Ussher et al. had found that body scanning also reduced irritability, restlessness and difficulty concentrating compared to control, so it is possible that the reduction in intrusive thoughts is also partly due to reductions in negative affect, which is specified by Kavanagh, Andrade and May (2005) as being one of the triggers for intrusions. An obvious extension of this work would be to explore further attentional control paradigms that do not involve mood changes.

Further studies on attentional control and intrusive thoughts could seek ways to resolve the relative contributions of affect, imagery, and executive load as ways of reducing the frequency and duration of smoking related thoughts. As a component of quit-smoking techniques, any cognitive strategy for reducing the impact of intrusive thoughts upon behaviour has the advantage that it requires no equipment and can be carried out privately, when and where the individual feels at risk of experiencing cravings. Techniques that require a high central executive load, however, will also interfere with a wide range of other concurrent tasks, and so may not be practical for everyday use. However, previously reported relationships between mindfulness and reactions to intrusive thoughts, including craving (Berry, May, Andrade \& Kavanagh, 2009) suggest that habitual awareness of one's 
environment and bodily sensations may help reduce craving. Future research should test whether training in mindfulness, or components of mindfulness such as body scanning, can have lasting effects on craving (as the Ussher et al. results suggest) without the cognitive load imposed by body scanning when it is still a novel task for participants.

Our findings provide a theoretical motivation for data suggesting that body scanning may be a useful addition to the repertoire of cognitive techniques taught to smokers who wish to quit, and by doing so open up the way for future research to refine and widen the applicability of such techniques.

\section{References}

Achtziger, A., Gollwitzer, P. M., \& Sheeran, P. (2008). Implementation intentions and shielding goal striving from unwanted thoughts and feelings. Personality and Social Psychology Bulletin, 34, 381-393. doi:10.1177/0146167207311201

Antrobus, J. (1968). Information theory and stimulus independent thought. British Journal of Psychology, 59, 423-430. doi:10.1111/j.2044-8295.1968.tb01157.

Berry, L.-M., May, J. Andrade, J. \& Kavanagh, D. (2009) Emotional and behavioural reaction to intrusive thoughts. Assessment. 17(1), 126-137. doi:10.1177/1073191109344694

Kavanagh, D. J., Andrade, J. \& May, J. (2005). Imaginary relish and exquisite torture: The elaborated intrusion theory of desire. Psychological Review, 112, 446-467. doi:10.1037/0033-295X.112.2.446

Kemps, E., \& Tiggemann, M. (2007). Modality-specific imagery reduces cravings for food. An application of the elaborated intrusion theory of desire to food craving. Journal of Experimental Psychology: Applied, 13(2), 95-104. doi:10.1037/1076-898X.13.2.95

Kemps, E., Tiggemann, M., Woods, D., \& Soekov, B. (2004). Reduction of food cravings through concurrent visuospatial processing. International Journal of Eating Disorders, 36, 31-40. doi: 10.1002/eat.20005

Killen, J. D., \& Fortmann, S. P. (1997). Craving is associated with smoking relapse: Findings from three prospective studies. Experimental and Clinical Psychopharmacology, 5, 137-142. doi:10.1037//1064-1297.5.2.137 
Body scanning reduces intrusive thoughts

Lemmens, V., Oenema, A., Knut, I.,K., Brug, J. (2008). Effectiveness of smoking cessation interventions among adults: a systematic review of reviews. European Journal of Cancer Prevention, 17 (6), 535-44. doi: 10.1097/CEJ.0b013e3282f75e48

May, J., Andrade, J., Batey, H., Berry, L.-M. \& Kavanagh, D. (2010) Less food for thought: Impact of Attentional Instructions on Intrusive Thoughts about Snack Foods. Appetite, 55(2), 279-287. doi:10.1016/j.appet.2010.06.014

May, J., Andrade, J., Panabokke, N. \& Kavanagh, D. (2004) Images of Desire: Cognitive Models of Craving. Memory, 12(4), 447-461. doi:10.1080/09658210444000061

May, J., Andrade, J., Panabokke, N. \& Kavanagh, D. (2010) Visuospatial tasks suppress craving for cigarettes. Behaviour Research and Therapy, 48, 476-485. doi:10.1016/j.brat.2010.02.001

Robinson, T. E., \& Berridge, K. C. (2000). The psychology and neurobiology of addiction: an incentive-sensitization view. Addiction, 95, S91-S117. doi:10.1080/09652140050111681

Salkovskis, P. M., \& Reynolds, M. (1994). Thought suppression and smoking cessation. Behaviour Research and Therapy, 32(2), 193-291. doi:10.1016/0005-7967(94)90112-0

Shiffman, S., Engberg, J., Paty, J., Perz, W. G., Gnys, M., Kassel, J., et al. (1997). A day at a time: predicting smoking lapse from daily urge. Journal of Abnormal Psychology, 106, 104-116. doi:10.1037//0021-843X.106.1.104

Taylor, A.H., Ussher, M.H. \& Faulkner, G. (2007). The acute effects of exercise on cigarette cravings, withdrawal symptoms, affect and smoking behaviour: a systematic review, Addiction, 102, 534-543. doi:10.1111/j.1360-0443.2006.01739.x

Teasdale, J. D., Proctor, L., Lloyd, C. A. \& Baddeley, A. D. (1993). Working-Memory and Stimulus-Independent Thought: Effects of Memory Load and Presentation Rate. European Journal of Cognitive Psychology, 5, 417-433. doi:10.1080/09541449308520128

Tiffany, S. T., \& Drobes, D. J. (1991). The development and initial validation of a questionnaire on smoking urges. British Journal of Addiction, 86, 1467-1476. doi:10.1111/j.1360-0443.1991.tb01732.x 
U.S. Department of Health and Human Services. (2008). Treating tobacco use and dependence: 2008 update of clinical practice guidelines. Rockville, MD. Retrieved 6/6/2011 from http://www.ncbi.nlm.nih.gov/books/NBK12239/

Ussher, M., Cropley, M., Playle, S., Mohidin, R., \& West, R. (2009) Effect of isometric exercise and body scanning on cigarette cravings and withdrawal symptoms. Addiction, $104,1251-1257$.

Ussher, M., West, R., Doshi, R. \& Sampuran, A.K. (2006). Acute effect of isometric exercise on desire to smoke and tobacco withdrawal symptoms. Human Psychopharmacology: Clinical \& Experimental, 21, 39-46. doi:10.1111/j.1360-0443.2009.02605.x

Versland, M., \& Rosenberg, H. (2007). Effects of brief imagery interventions on craving in college student smokers. Addiction Research and Theory, 15(2), 177-187. doi:10.1080/16066350701200582

Wegner, D. M. (1989). White bears and other unwanted thoughts: Suppression, obsession, and the psychology of mental control. New York: Viking/Penguin.

West, R.J., Hajek, P. \& Belcher, M. (1989) Severity of withdrawal symptoms as a predictor of outcome of an attempt to quit smoking. Psychological Medicine, 19, 981-985. doi:10.1017/S0033291700005705

West, R., Walia, A., Hyder, N., Shahab, L., \& Michie, S. (2010) Behavior change techniques used by the English Stop Smoking Services and their associations with short-term quit outcomes. Nicotine \& Tobacco Research, 12(7) ,742-747. doi:10.1093/ntr/ntq074

Zhou, X., Nonnemaker, J., Sherrill, B., Gilsenan, A. W., Coste, F., \& West, R. (2009). Attempts to quit smoking and relapse: factors associated with success or failure from the ATTEMPT cohort study. Addictive Behaviors, 3, 365-373. doi:10.1016/j.addbeh.2008.11.013 
Body scanning reduces intrusive thoughts

Figure 1: In the Experimental session, smoking related thoughts dropped during the bodyscan recording and then rose again, but they remained at the same level throughout the control session (bars represent 95\%CI).

Figure 2: Craving rose steadily throughout the control session; although it started off at a higher level in the experimental session it dropped during the bodyscan recording (bars represent 95\%CI). 


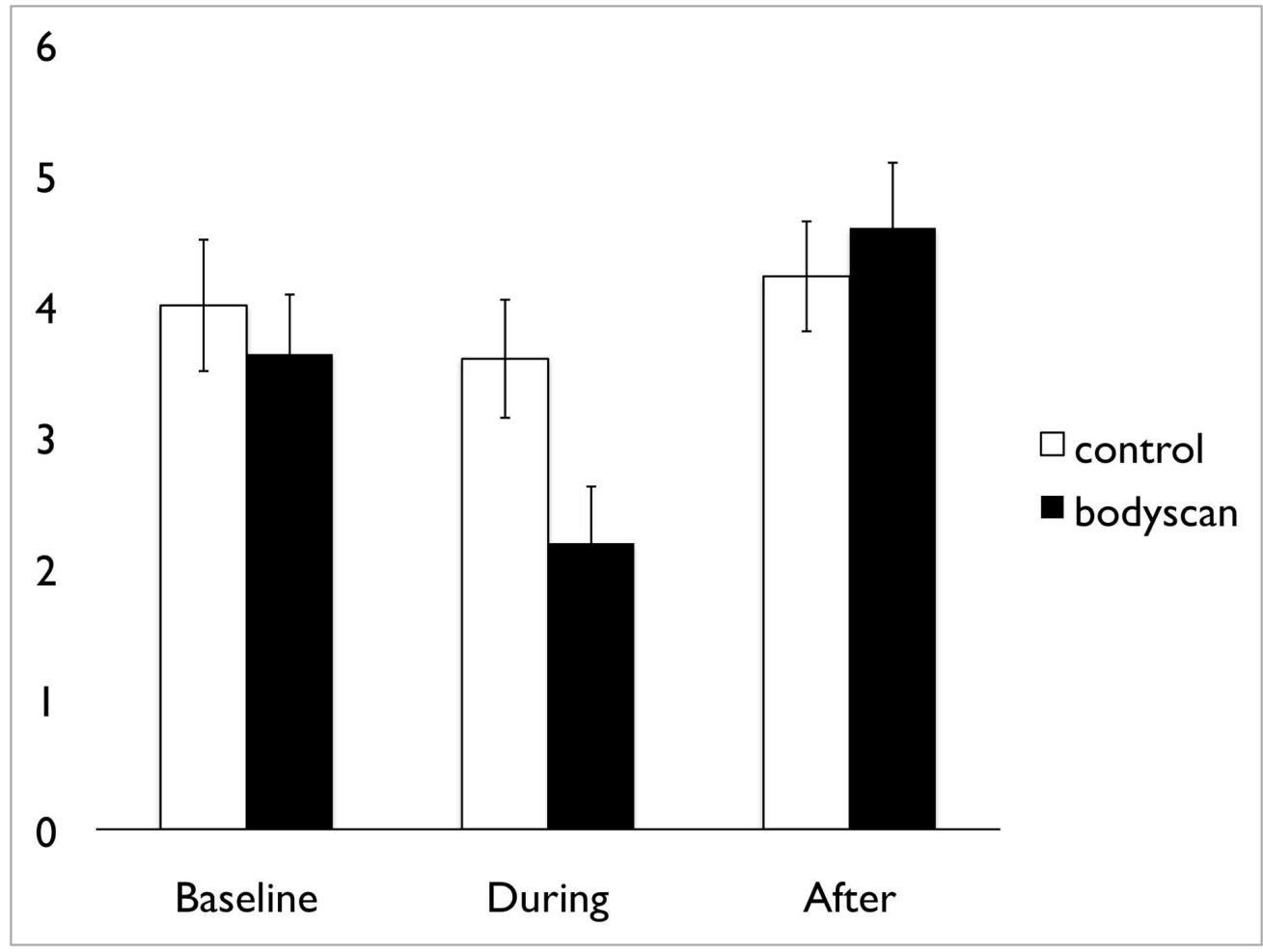

$675 \times 508 \mathrm{~mm}(72 \times 72 \mathrm{DPI})$ 


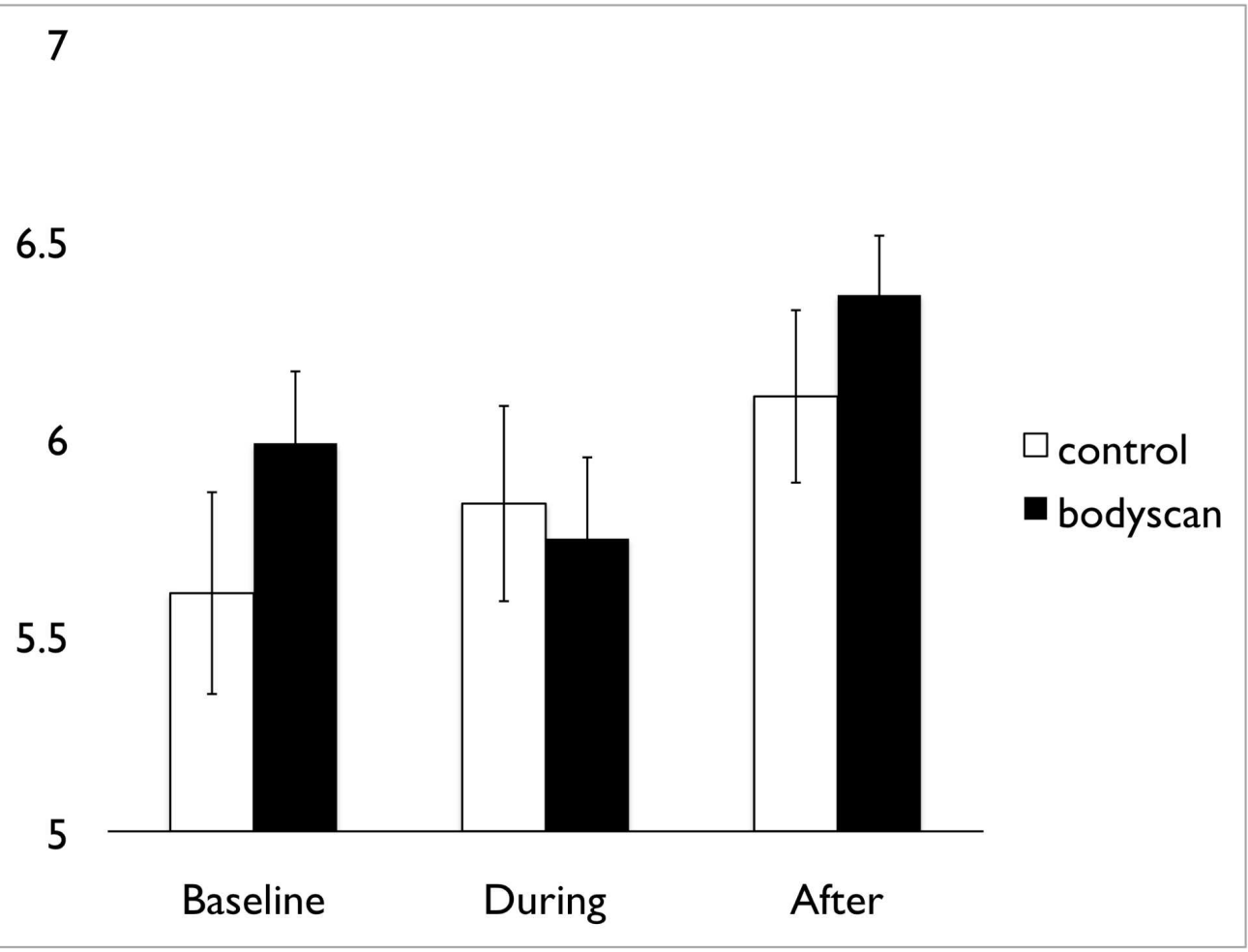

$680 \times 512 \mathrm{~mm}(72 \times 72 \mathrm{DPI})$ 